\title{
UWB Single Port Log Periodic Toothed Terahertz Antenna Design Based on Graphene Artificial Magnetic Conductor
}

\author{
Hussein A. Abdulnabi ${ }^{1}$, Refat T. Hussein ${ }^{2} \&$ Raad S. Fyath ${ }^{3}$ \\ ${ }^{1}$ Dept. of Electrical Eng., UOT, Iraq \\ ${ }^{2}$ Dept. of Communication Eng.,UOT, Baghdad, Iraq \\ ${ }^{3}$ Dept. of Computer Eng., AL-Nahrain University, Iraq \\ Correspondence: Hussein A. Abdulnabi, Dept. of Electrical Eng., UOT, Iraq. E-mail: \\ Hussein_ali682@yahoo.com,140100@uotechnology.edu.iq,rsfyath@yahoo.com
}

Received: October 30, 2016

Accepted: November 21, 2016 Online Published: Janauary 14, 2017

doi:10.5539/mas.v11n3p86

URL: http://dx.doi.org/10.5539/mas.v11n3p86

\begin{abstract}
In this work, a single port exponential tapered toothed log periodic antenna based on graphene artificial magnetic conductor (AMC) is suggested for ultra-wideband (1-10) THz operation. The resonance frequency of the proposed antenna can be tuned by changing the connected DC voltage which leads to variation in the chemical potential of the graphene.The radiating toothed log periodic antenna consists of gold patch placed on $25 \times 25$ graphene patches which act as an AMC surface unit. Exponential taper is used to satisfy impedance matching between the antenna and the feeder over the frequency range. The simulation results reveal that $90 \%$ of frequency range satisfies $s_{11}<-10 d B$ when the chemical potential is $1 \mathrm{eV}$.
\end{abstract}

Keywords: Graphene, artificial magnetic conductor, terahertz antenna, toothed log periodic antenna, UWB antenna

\section{Introduction}

Graphene has been named the simplest complex material whichhas drawn increasing attention in recent years due to its unique properties and advantages. In fact, graphene is used in many fields including mechanical, thermal and electrical applications (Geim \& Novoselov, 2007; Grigorenko, Polini \& Novoselov, 2012). The surface conductivity of the graphene can be varied by changing the applied electrical potential (SensaleRodr'1guez, Yan, Liu, Jena \& Xing, 2013; Low \& Avouris, 2014), thus many graphene based-devices such as antennas, filters, absorbers, and polarizer's have been suggested for bands in microwave, terahertz and optical frequencies (Fallahi \& Perruisseau-Carrier, 2012; Andryieuski, \& Lavrinenko, 2013). Graphene-based THz and photonic antennas were also developed in (Wu, Tuncer, Naeem, Yang, Cole, Milne \& Hao, 2014; Xu, Lu, Jiang $\&$ Dong, 2012) for different applications.

The graphene can be used to design $\mathrm{THz}$ antennas, as radiating part (Esquius-Morote, G'omez-D'iaz \& Perruisseau-Carrier, 2014; Tamagnone, G'omez-D'1az, Mosig \& Perruisseau-Carrier, 2012), parasitic component, or high impedance surfaces (HIS) usually based on AMC configuration (Dragoman, Muller, Dragoman, Coccetti \& Plana, 2010; Tamagnone, Gomez Diaz, Mosig \& Perruisseau-Carrier, 2013). The AMC is a planar array of periodic surface which can improve the control of electromagnetic wave radiation. Thus this structure has been broadly utilized in the design of some types of antennas such as low profile leaky wave antenna operating at microwave regime with high efficiency and gain in correlation with conventional ground plane. Also adding active HIS (Huang, Wu, Tang \& Mao, 2012) elements loaded with varactor diodes to the antennas enables them to beam steering and easy frequency tuning (Guzman-Quiros, Gomez-Tornero, Weily \& Guo, 2012; Sievenpiper, Schaffner, Song, Loo \& Tangonan, 2003). It is also possible to insert periodic graphene patches as antenna ground. A tunable terahertz antenna based on graphene AMC with relatively narrow bandwidth was presented in (Wang, Zhao, Hu \& Zhang, 2013). In (Wang, Li, Zhao \& Hu, 2013) many shapes of grapheme-based AMC were studied and compared. The graphene biased reflective array was also applied for antenna configuration to get frequency tuning and beam reconfiguration (Esquius-Morote, G'omez-D'1az \& Perruisseau-Carrier, 2014; Tamagnone, Gomez Diaz, Mosig \& Perruisseau-Carrier, 2013).

In this work, a single port novel tunable UWB antenna depending on AMC array is proposed. The antenna has 
log periodic toothed shape with exponential tapered transmission line implemented over graphene patche array which acts as an AMC. The applied voltage is used to tune this antenna in order to wide its bandwidth.

\section{Background}

\subsection{Graphene Conductivity}

The graphene can displayed as an infinitesimally flimsy surface which is portrayed by surface conductivity $\sigma s\left(\omega, \tau, \mu_{C}, T\right)$. The graphene conductivity Drude model in intraband can be written by (Wang, Zhao, Hu \& Zhang, 2013)

$$
\sigma_{S}(\omega)=\frac{\mathrm{e}^{2} \mathrm{k}_{\mathrm{B}} T \tau}{(1+\mathrm{j} \omega \tau) \pi \hbar^{2}}\left[\frac{\mu \mathrm{c}}{\mathrm{k}_{\mathrm{B}} \mathrm{T}}+2 \ln \left(\mathrm{e}^{\frac{-\mu_{\mathrm{c}}}{\mathrm{k}_{\mathrm{BT}}}}+1\right)\right]
$$

Where $\tau$ is the scattering time, $\omega$ is the angular frequency, $\mu_{C}$ is the chemical potential in $\mathrm{eV}$, which can be changed by chemical doping process or by using $\mathrm{DC}$ voltage, e is the electron charge, $\mathrm{T}$ is the absolute temperature, $\mathrm{k}_{\mathrm{B}}$ is Boltzmann constant, and $\mathrm{h}$ is reduced Planck's constant.

The graphene surface impedance can be expressed as

$$
Z_{S}(\omega)=\frac{1}{\sigma_{S}(\omega)}
$$

\subsection{Graphene-Based AMC}

The graphene is used as an AMC unit cell which consists of a periodic of square patches with dimension $\mathrm{D}$ and the gap between adjacent patches is $\mathrm{g}$ as in Figure 1 (Wang, Zhao, Hu \& Zhang, 2013).

The patch array at terahertz band surface impedance can be written as (Wang, Li, Zhao \& Hu, 2013)

$$
Z_{g}=j\left(\frac{D}{D-g} \frac{1}{\sigma}-\frac{1}{\omega C_{e f f}}\right)=\frac{1}{j \omega C_{g}(\omega)}
$$

where $\mathrm{C}_{\mathrm{g}}$ represents the capacitance between adjacent graphene patches

$$
C_{\text {eff }}=\frac{1}{\pi} \varepsilon_{o}\left(\varepsilon_{r}+1\right) D \ln \left[\csc \left(\frac{\pi}{2} \frac{g}{D}\right)\right]
$$

Here $\varepsilon_{o}$ is the permittivity of free space, $\varepsilon_{r}$ is the substrate relative permittivity, and $C_{e f f}$ is the capacity for the background and patch geometry.

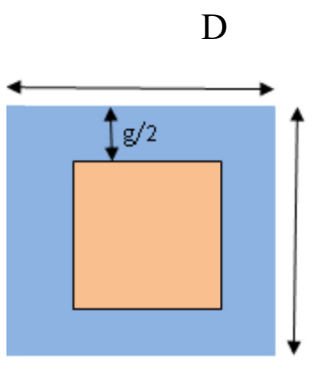

(a) AMC unit cell

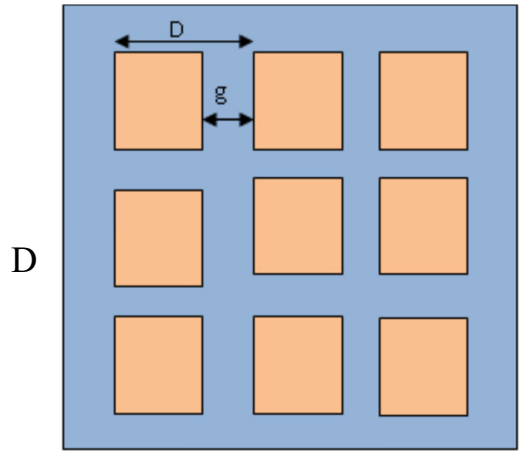

(b) AMC graphene patches array

Figure 1. Graphene-based artificial magnetic conductor (Wang, Li, Zhao \& Hu, 2013)

The circuit model representing the equivalent circuit of graphene patches array mounted on grounded substrate is shown in Figure 2 (Wang, Zhao, Hu \& Zhang, 2013). 


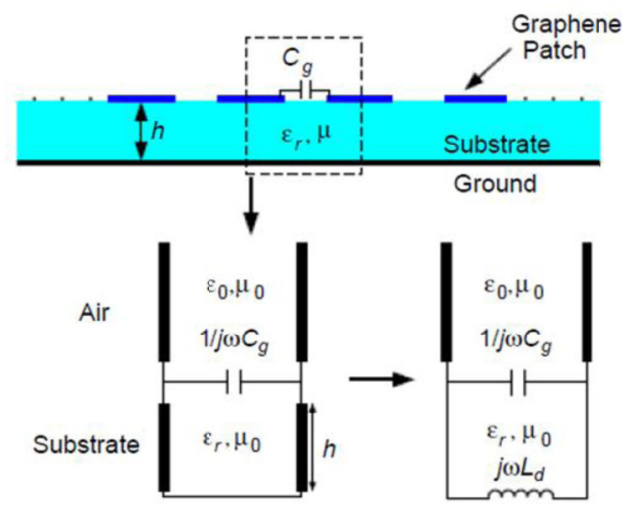

Figure 2. Equivalent circuit model for a graphene patches array mounted on groundedsubstrate

\subsection{Log Periodic Antenna}

Log periodic antenna (LPA) is still interesting although many decades passed. It provides frequency independence properties for the antenna over wide band of frequency. In fact, theoretically log periodic antenna is a class of antennas for which pattern and impedance independent on frequency for unlimited band of frequencies. The impedance and pattern of LPA structures is shaped so thatrepeat periodically in relation with the frequency logarithm, as in Figure 3.

$$
\begin{gathered}
\tau=\frac{R_{N+1}}{R_{N}} \\
\delta=\frac{r_{N}}{R_{N}}
\end{gathered}
$$

where $R_{N}$ and $r_{N}$ are the distance from the center of the antenna to the outer and inner radiuses of the tooth $\mathrm{N}$ respectively, $\tau$ is the ratio between two outer radiuses of successive teeth, and $\delta$ is the ratio between inner radius to the outer radius for any tooth. The structure shape and scaling factor $\tau$ can be used such that the changing of the impedance and pattern over each period is small, the result being an extremely wideband antenna. The feeding of the two parts of the antenna is at the vertices either by a coaxial line or by a balanced two-wire line. The upper and lower frequency limits are achieved when the shortest and longest teeth, respectively, are around 0.25 wavelength long.

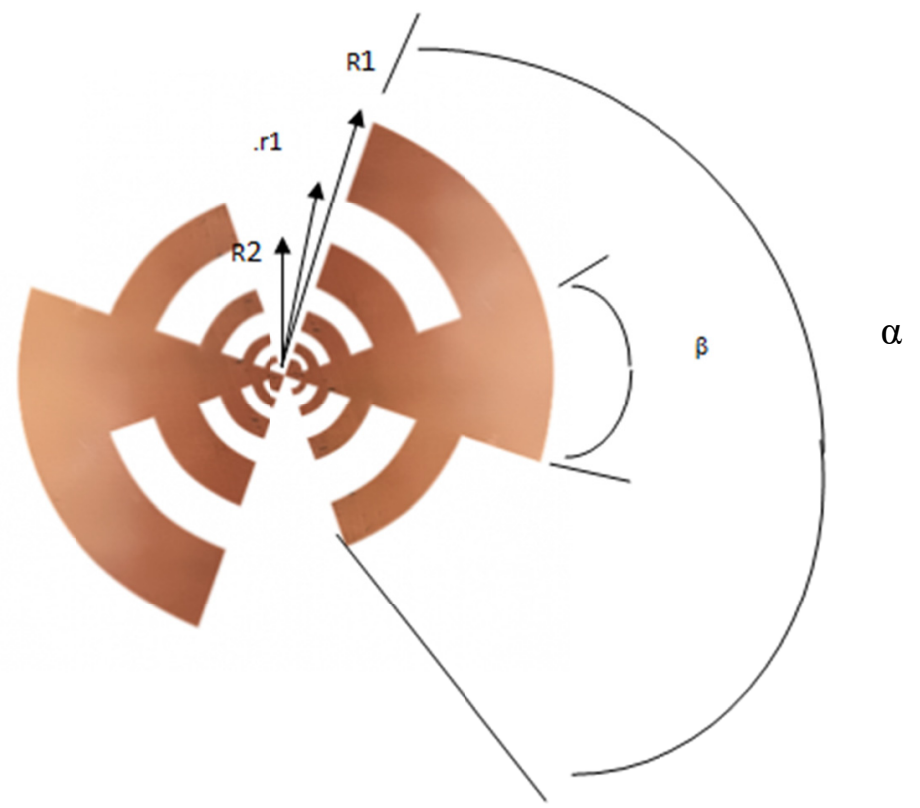

Figure 3. Log periodic toothed antenna

\subsection{Impedance Matching}


Tapered line is used in this work to increase the matching between the antenna and the feeder. Typically the characteristic impedance of the transmission line is $50 \Omega$,while the input impedance of the proposed wideband antenna is $200 \Omega$. Thus an exponential line taper is used to match the $50 \Omega$ of the feeder to the $200 \Omega$ of the antenna, as shown in Figure 4. The exponential line is characterized by (Pozar, 2011)

$$
Z(z)=Z_{o} e^{\alpha z} \text { for } 0 \leq z \leq L
$$

where $Z_{o}=Z(0)$ and

$$
a=\frac{1}{L} \ln \left(\frac{Z_{L}}{z_{O}}\right)
$$

Here $Z(L)$ is the characteristic impedance of the transmission line at distance $\mathrm{L}$, i.e., $\mathrm{Z}_{\mathrm{L}} \equiv \mathrm{Z}(\mathrm{L})$.

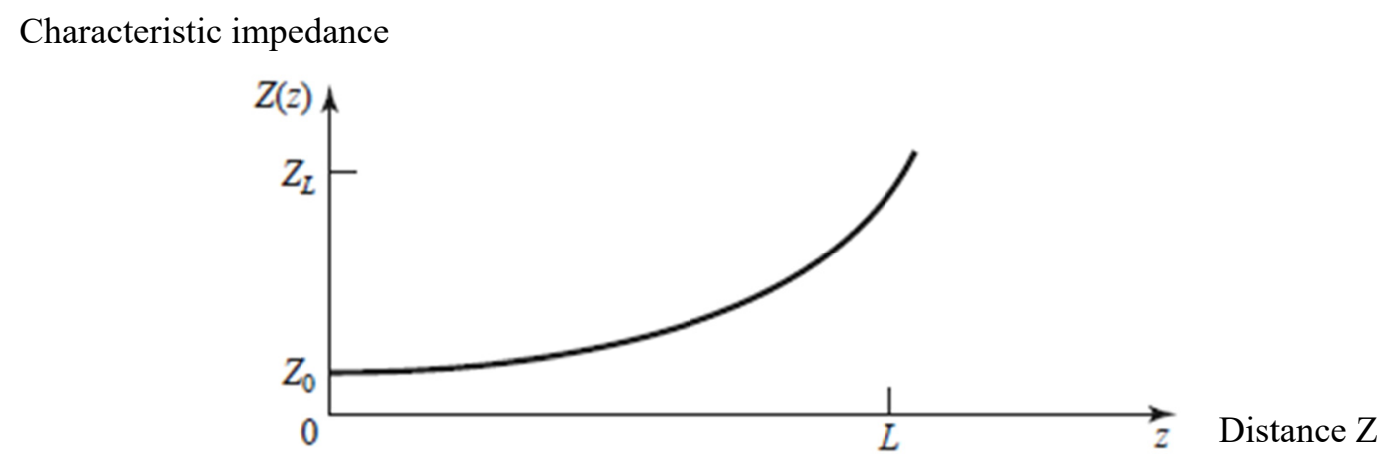

Figure 4.Variation of the characteristic impedance along the exponential taper

\section{Proposed Antenna Model}

In our work, the proposed log periodic toothed antenna has a structure of $\alpha=120^{\circ}, \beta=45^{o}$, where $\alpha$ is the tooth angle, $\beta$ is the bow angle and $\tau=\sigma^{2}=0.5$, as shown in Figure 5a.

This proposed antenna is based on AMC and composed of $25 \times 25$ array of periodic square conductive graphene sheets. A log periodic toothed antenna from gold material is placed on the graphene-depend AMC ground plane, as shown in Figure 5b. A grounded $\mathrm{SiO}_{2}$ material of thickness $10 \mu \mathrm{m}$ is representing the AMC substrate. A silicon wafer of thickness $300 \mu \mathrm{m}$ is used under the substrate. A50 $\mathrm{nm}$ from polycrystalline silicon material is placed above the quartz is thick layer and $\mathrm{Al}_{2} \mathrm{O}_{3}$ of $10 \mathrm{~nm}$-thick film in sequence, (Wang, Zhao, Hu \& Zhang, 2013). The AMC unit consists of $25 \times 25$ graphene square shape patches with $g=1 \mu \mathrm{m}$ and $D=9 \mu \mathrm{m}$. The graphene patches are connected by a $60 \mathrm{~nm}$-wide graphene to keep all AMC units at the same $\mu_{c}$ when a DC voltage is connected between the polycrystalline silicon and the AMC. A $2 \mu m$-thick $\mathrm{SiO}_{2}$ material is placed on the graphene AMC, and the gold antenna is placed on $\mathrm{Sio}_{2}$ layer (Wang, Zhao, Hu \& Zhang, 2013).

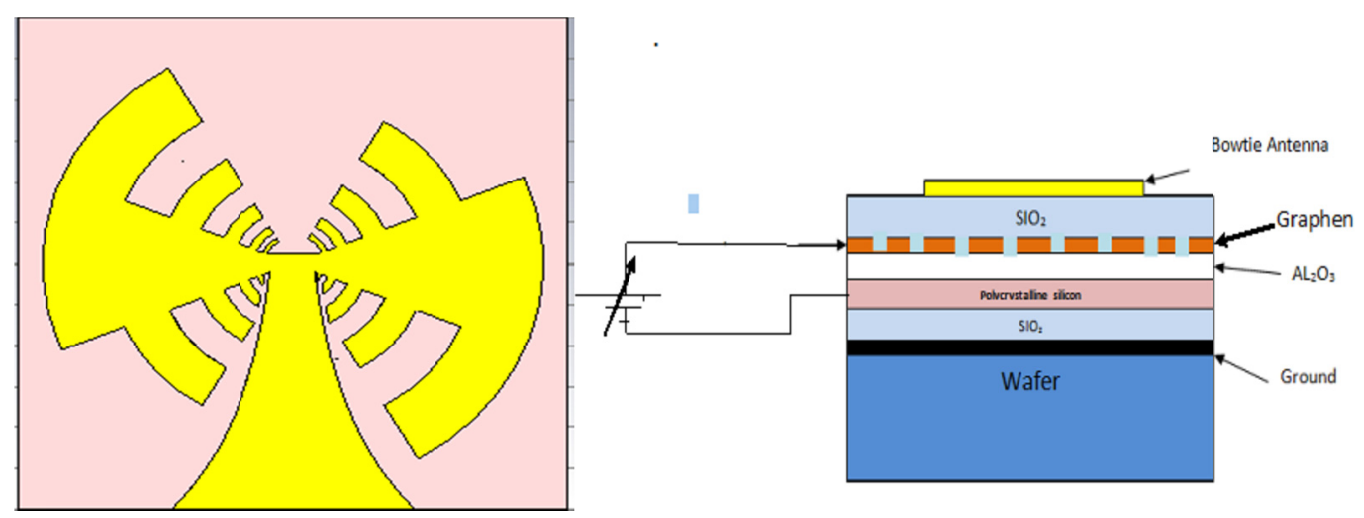

(a) Top view

(b) side view

Figure 5. ProposedAMC-basedantenna structure 


\section{Simulation Results and Discussion}

Simulation results are obtained using CST Studio ver.2014 for many values of chemical potential $\mu_{C}$. Results related to $\mu_{C}=0.1 \mathrm{eV}$ and $1 \mathrm{eV}$ are given in this section, while the results relate to other values of $\mu_{C}$ are given in the Appendix. Figure 6a shows the scattering parameter $\mathrm{S}_{11}$ in $\mathrm{dB}$ of the proposed antenna for $\mu_{C}=0.1 \mathrm{eV}$. The operating bandwidth extends from $(1.0-2.8) \mathrm{THz}$, at which $\mathrm{S}_{11}<-10 \mathrm{~dB}$, while Figure $6 \mathrm{~b}$ shows the broadband gain of the proposed antenna when $\mu_{C}=0.1 \mathrm{eV}$. The antenna has gain $\geq 5 \mathrm{~dB}$ for the entire frequency band $(6.1-10) \mathrm{THz}$.
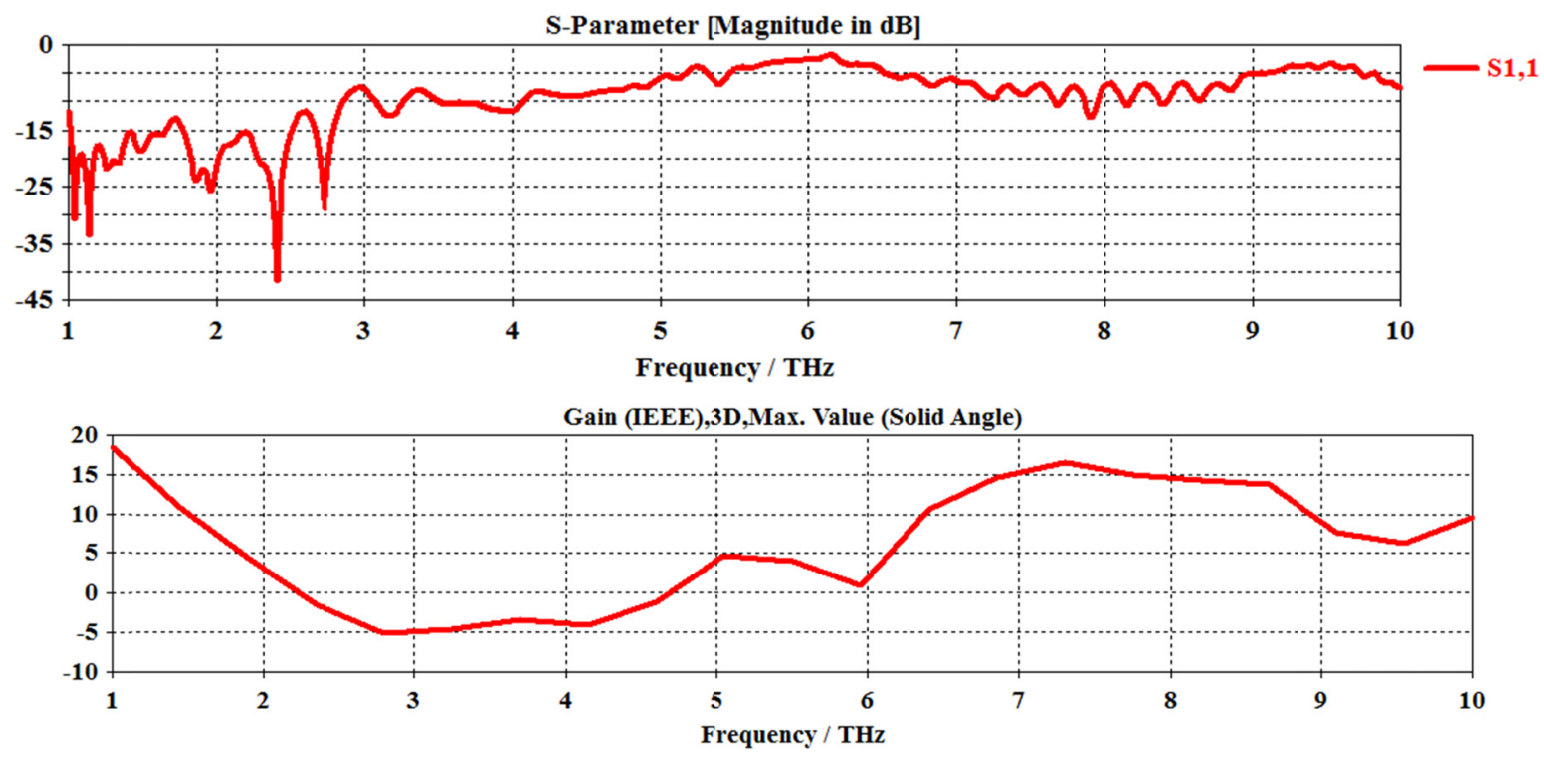

(b) Antenna gain

Figure 6. Proposed antenna characteristics when $\mu_{C}=0.1 \mathrm{eV}$.

Figure 7a shows the scattering parameter $\mathrm{S}_{11}$ in $\mathrm{dB}$ of the proposed antenna for $\mu_{C}=1 \mathrm{eV}$. The operating bandwidth extends from $(2.4-8.3) \mathrm{THz}$ and from $(9-10) \mathrm{THz}$. Further, there are resonance frequencies at $(1,1.5$, and 2$) \mathrm{THz}$ at which $S 11<-10 \mathrm{~dB}$.

Figure $7 \mathrm{~b}$ shows the broadband gain of the proposed antenna for $\mu_{C}=1 \mathrm{eV}$. It has very good gain between -2 and $10 \mathrm{~dB}$ for the entire frequency band.

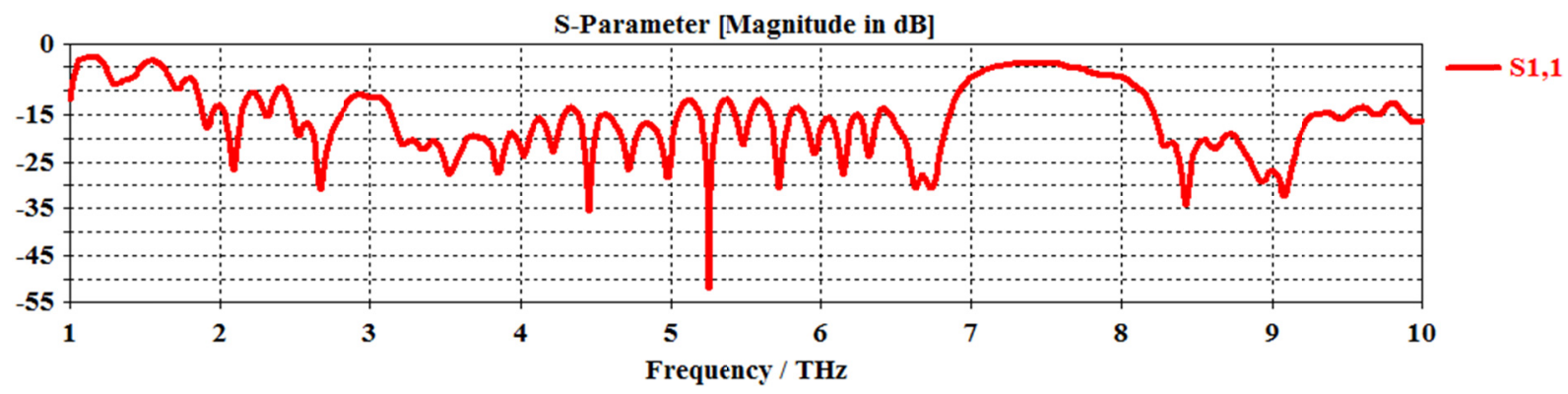

(a) Scattering parameter $S_{11}$ 


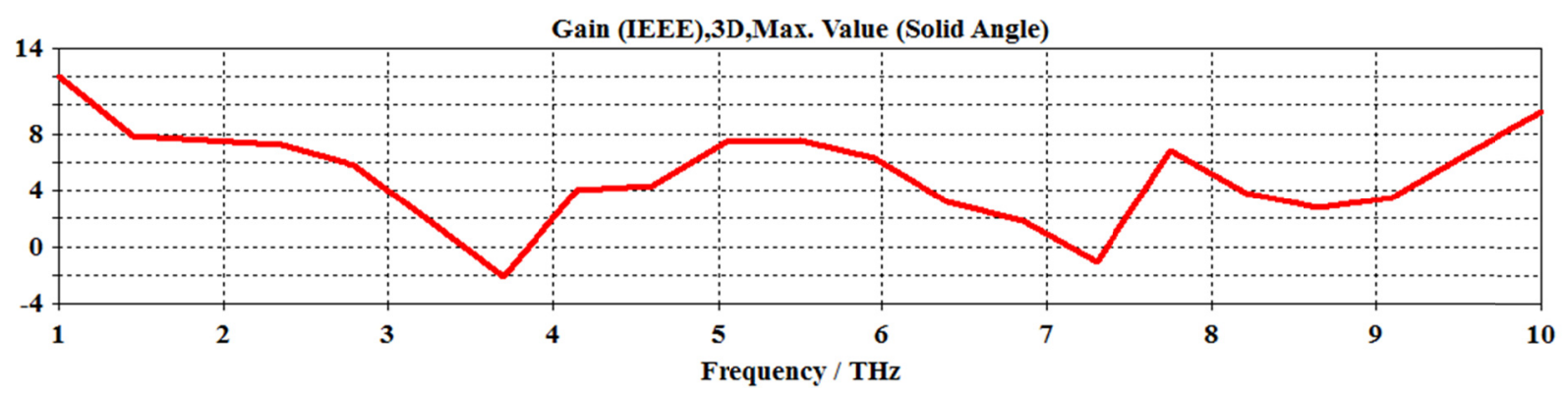

(b) Gain spectrum

Figure 7. Proposed antenna characteristics when $\mu_{C}=1 \mathrm{eV}$

Figure 8 summarize the frequency bands at different values of chemical potential $\mu_{C}=(0.1-1) \mathrm{eV}$. The cumulative bandwidth, calculated as the sum of the bandwidths of different bands at which $\mathrm{S}_{11}<-10 \mathrm{~dB}$, is mentioned in Table (1).

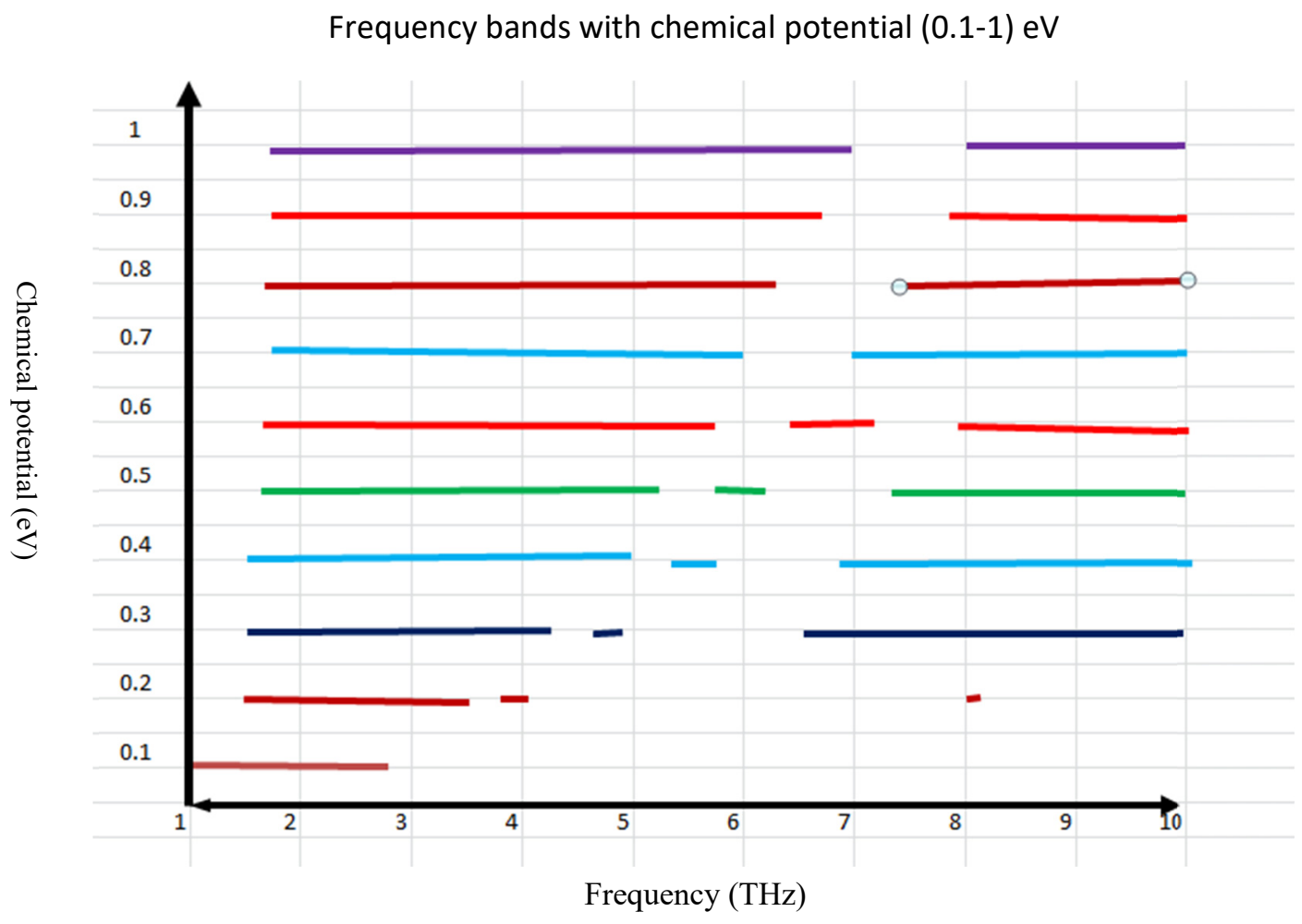

Figure 8. Frequency bands for different values of chemical potential $\mu_{C}=(0.1-1) \mathrm{eV}$

Table 1. Variation of the cumulative bandwidth with $\mu_{\mathrm{c}}$

\begin{tabular}{cc}
\hline Chemical potential $\boldsymbol{\mu}_{\mathbf{c}}(\mathbf{e V})$ & Cumulative bandwidth $(\mathbf{T H z})$ \\
\hline 0.1 & 1.80 \\
0.2 & 2.50 \\
0.3 & 6.45 \\
0.4 & 6.80 \\
0.5 & 6.90 \\
0.6 & 6.92 \\
0.7 & 7.20 \\
0.8 & 7.20 \\
\hline
\end{tabular}




\begin{tabular}{cc}
\hline 0.9 & 7.30 \\
1 & 7.35 \\
\hline
\end{tabular}

\section{Conclusions}

In our work, a tunable antenna based on graphene as artificial magnetic conductor has been designed to achieve UWB operating frequency band, $(1-10) \mathrm{THz}$ at which $\mathrm{S}_{11}<-10 \mathrm{~dB}$. The antenna itself has been formed as $\log$ periodic toothed antenna wherean exponential transmission line taper is used to increase the matching between the antenna and the feeder. The simulation results reveal that the antenna cumulative bandwidth increases by increasing the chemical potential. The highest cumulative bandwidth of $\mathrm{S}_{11}<-10 \mathrm{~dB}$ of the proposed antenna is equal to $6.86 \mathrm{THz}$ at $\mu_{C}=1 \mathrm{eV}$.

\section{Acknowledgment}

One of the authors, Hussein Ali would like to thank the college of Engineering at AL- Mustansiriyah university ,Baghdad, Iraq, http://uomustansiriyah.edu.iq/index.php?id_dept=5 for offering the PhD. Scholarship

\section{References}

Andryieuski, A., \& Lavrinenko, A. V. (2013). Graphene metamaterials based tunable terahertz absorber: Effective surface conductivity approach,:Opt. Exp. https://doi.org/10.1364/OE.21.009144

Carraso, E., \& Carrier, J. P. (2013). Reflectarray antenna at terahertz usingGraphene:IEEE Antennas Wireless Propag. Lett. http://dx.doi.org/10.1109/LAWP.2013.2247557

Costa, F., \& Monorchio, A. (2011). Design of subwavelength tunable andsteerablefabry-perot/leaky wave antennas: Prog. Electromagn Res. http://dx.doi.org/10.2528/PIER10111702

Dragoman, M., Muller, A. A., Dragoman, D., Coccetti, F., \& Plana, R. (2010). Terahertz antenna based on graphene:J. Appl. Phys. http://dx.doi.org/10.1063/1.3427536

Esquius-Morote, M., G'omez-D'iaz, J. S., \& Perruisseau-Carrier, J. (2014). Sinusoidally modulated graphene leaky-wave antenna for electronic beamscattering at THz," IEEE Trans. Terahertz Sci. Technol. http://dx.doi.org/10.1109/TTHZ.2013.2294538.

Fallahi, A., \& Perruisseau-Carrier, J. (2012). Design of tunable bi-periodicgraphenemetasurfaces,:Phys. Rev. B. http://dx.doi.org/10.1103/PhysRevB.86.195408

Filter, R., Farhat, M., Steglich, M., Alaee, R., Rockstuhl, C., \& Lederer, F. (2013). Tunable graphene antennas for selective enhancement of THz-emission,:Opt. Exp. https://doi.org/10.1364/OE.21.003737

Geim, A. K. (2009). Graphene Status and prospects:Science. .http://dx.doi.org/ 10.1126/science.1158877

Geim, A. K., \& Novoselov, K. S. (2007). The rise of graphene:Nature Mat. http://dx.doi.org/10.1038/nmat1849

Grigorenko, A. N., Polini, M., \& Novoselov, K. S. (2012). Graphene plasmonics,:Nature Photon. http://dx.doi.org/ 10.1038/nphoton.2012.262

Gulbahar, B., \& Akan, O. B. (2012). A communication theoretical modeling of single-layer graphene photodetectors and efficient multireceiver diversity combing. IEEE Trans. Nanotechnol. http://dx.doi.org/10.1109/TNANO.2012.2187068

Guzman-Quiros, R., Gomez-Tornero, J. L., Weily, A. R., \& Guo,Y. J. (2012). Electronically steerable 1-D Fabry-Perot leaky-wave antenna employing a tunable high impedance surface. IEEE Trans. Antennas Propag. http://dx.doi.org/10.1109/TAP.2012.2208089

Huang, Y., Wu, L. S., Tang, M., \& Mao, J. (2012). Design of a beam reconfigurable THz antenna with graphene-based switchable high-impedance surface:IEEE Trans. Nanotechnol. http://dx.doi.org/10.1109/TNANO.2012.2202288

Kim, J. T., \& Choi, C. G. (2012). Graphene-based polymer waveguide polarizer:Opt. Exp. https://doi.org/10.1364/OE.20.003556

Low, T., \& Avouris, P. (2014). Graphene plasmonics for terahertz to mid-infrared applications". ACS Nanohttp://dx.doi.org/10.1021/nn406627u

Padooru, Y. R., Yakovlev, A. B., Kaipa, C. S. R., Hanson, G. W., Medina, F., \& Mesa, F. (2013). Dual capacitive-inductive nature of periodic graphene patches: Transmission characteristics at low-terahertz frequencies," Phys. https://doi.org/10.1103/PhysRevB.87.115401 
Pozar, D. M. (2011). Microwave engineering:(4th Ed.), Wiley.

Rano, F. (2008). Graphene terahertz plasmon oscillators," IEEE Trans. Nanotechnol. http://dx.doi.org/10.1109/TNANO.2007.910334

Sensale - Rodr'iguez, B., Yan, R., Liu, L., Jena, D., \& Xing, H. G. (2013). Graphene for reconfigurable terahertz optoelectronicsProc. IEEE.http://dx.doi.org/10.1109/JPROC.2013.2250471

Sievenpiper, D. F., Schaffner, J. H., Loo, R., Tangonan, G., Ontiveros, S., \& Harold, R. (2002). A tunable impedance surface performing as a reconFigureurable beam steering reflector.IEEE Trans. Antennas Propag. http://dx.doi.org/10.1109/8.999631

Sievenpiper, D. F., Schaffner, J. H., Song, H., Loo, R. Y., \& Tangonan, G. (2003). Two-dimensional beam steering using an electrically tunable impedance surface: IEEE Trans. Antennas Propag. http://dx.doi.org/10.1109/TAP.2003.817558

Tamagnone, M., G'omez-D'1az, J. S., Mosig, J. R., \& Perruisseau-Carrier, J. (2012). Analysis and design of terahertz antennas based on plasmonic resonant graphene sheets," J. Appl. Phys., 112(11), 114-915. http://dx.doi.org/ http://dx.doi.org/10.1063/1.4768840

Tamagnone, M., Gomez Diaz, J. S., Mosig, J., \& Perruisseau-Carrier, J. (2013). Hybrid graphene-metal reconfigurable terahertz antenna," in Proc. Int. Microw. Symp. Seattle. http://dx.doi.org/10.1109/MWSYM.2013.6697756

Wang, X. C., Li, W. Y., Zhao, W. S., \& Hu, J. (2013). Comparative study on graphene-based artificial magnetic conductor (AMC).PIERS proceedings, Sweden, 496-499.

Wang, X. C., Zhao, W. S., Hu, J., \& Zhang, T. (2013). A novel tunable antenna at THz frequencies using graphene-based artificial magnetic conductor (AMC): Prog. Electromagn. Res. Lett. http://dx.doi.org/10.2528/PIERL13050203

Wu, B., Tuncer, H. M., Naeem, M., Yang, B., Cole, M. T., Milne, W. I., \& Hao, Y. (2014). Experimental demonstration of a transparent graphene millimeter wave absorber with $28 \%$ fractional bandwidth at 140 GHz:Sci. Rep. http://dx.doi.org/10.1038/srep04130

Xu, B. Z., Gu, C. Q., Li, Z., \& Niu, Z. Y. (2013). A novel structure for tunable terahertz absorber based on graphene:Opt. Exp. http://dx.doi.org/10.1364/OE.21.023803.

Xu, H. J., Lu, W. B., Jiang, Y., \& Dong, Z. G. (2012). Beam-scattering planar lens based on graphene," Appl. Phys. Lett. http://dx.doi.org/10.1038/srep33522

Yao, Y., Kats, M. A., Genevet, P., Yu, N., Song, Y., Kong, J., \& Capasso, F. (2013). Broad electrical tuning of graphene-loaded plasmonic antennas: Nano Lett. http://dx.doi.org/ 10.1021/n13047943

\section{Appendix}

This Appendix presents related to the spectrum of the scattering parameter S11 and the gain for the proposed antenna when $\mu \mathrm{c}$ varies from $0.2 \mathrm{eV}$ to $1 \mathrm{eVat}$ step of $0.1 \mathrm{eV}$

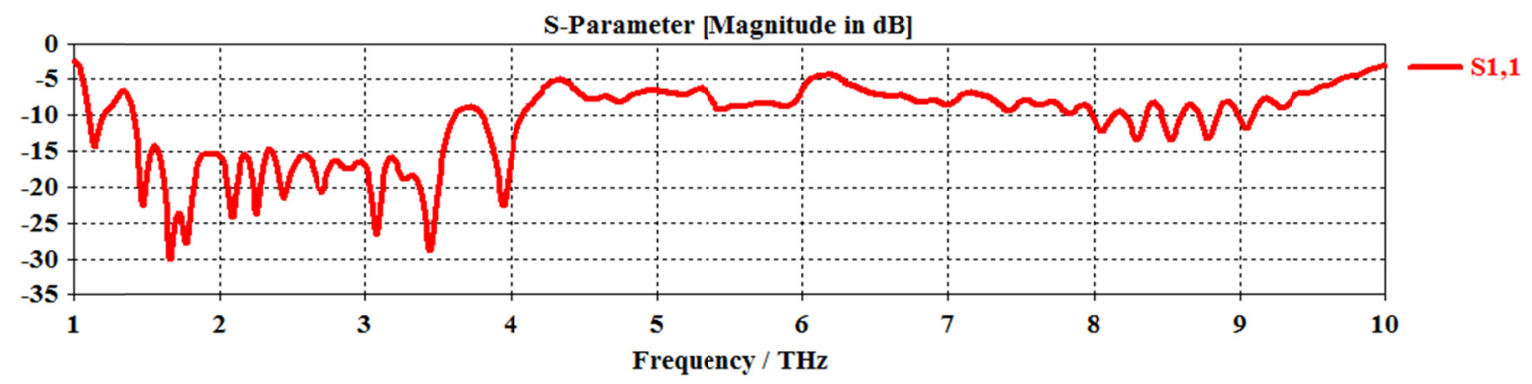

(a) Antenna scattering parameter $S_{11}$ 


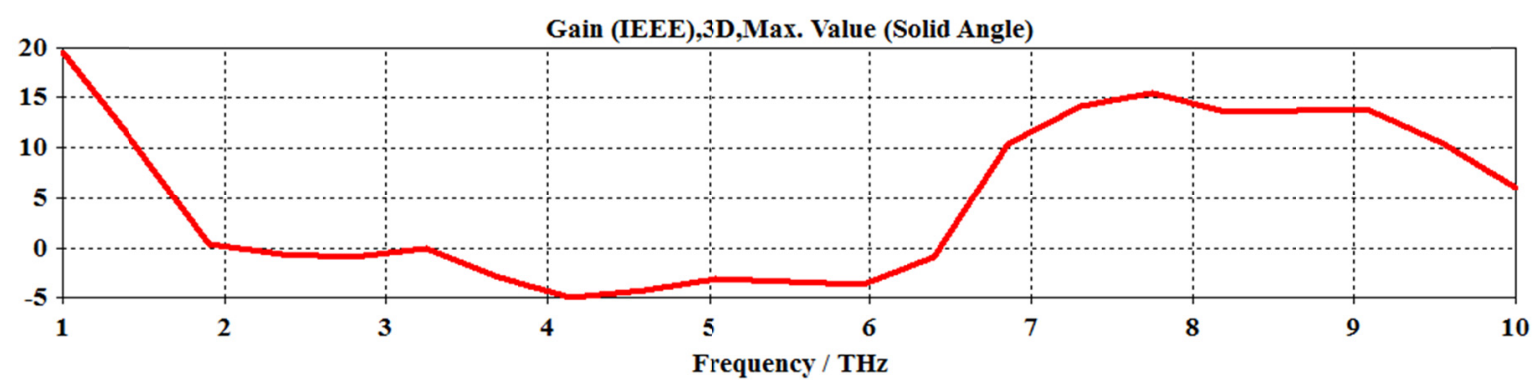

(b) Antenna gain

Figure A1. Antenna scattering parameter $S_{11}$ (a) and antenna gain (b) when $\mu_{\mathrm{c}}=0.2 \mathrm{eV}$

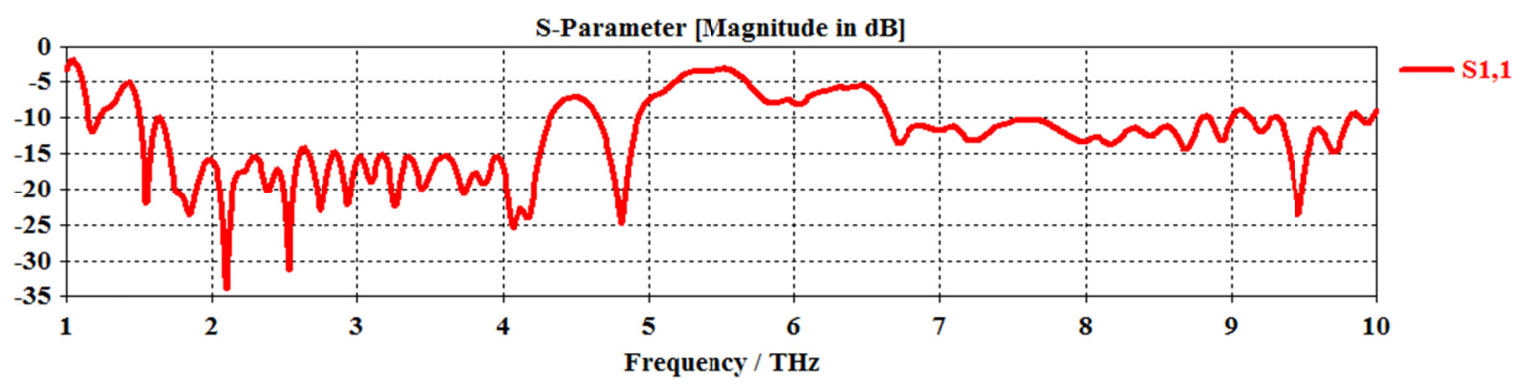

(a) Antenna scattering parameter $S_{11}$

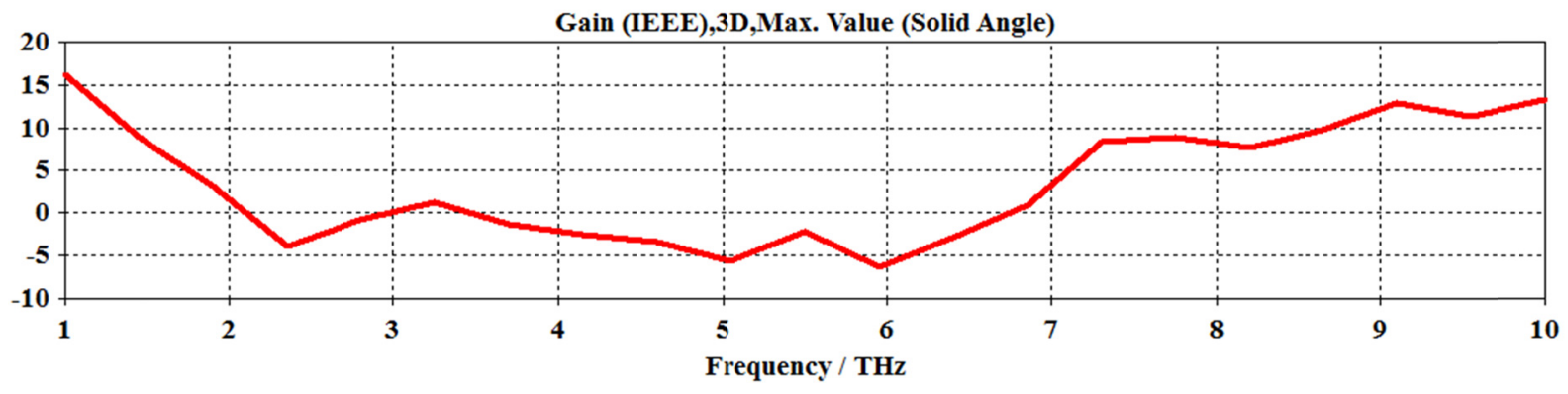

(b) antenna gain

Figure A2. Antenna scattering parameter $S_{11}$ (a) and antenna gain (b) when $\mu_{\mathrm{c}}=0.3 \mathrm{eV}$

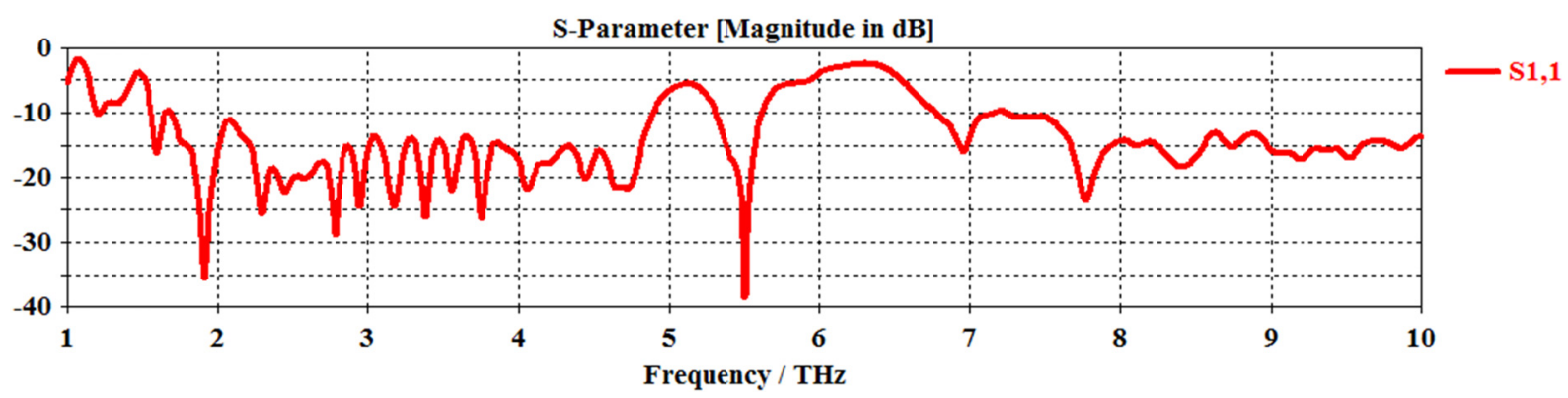

(a) Antenna scattering parameter $S_{11}$ 


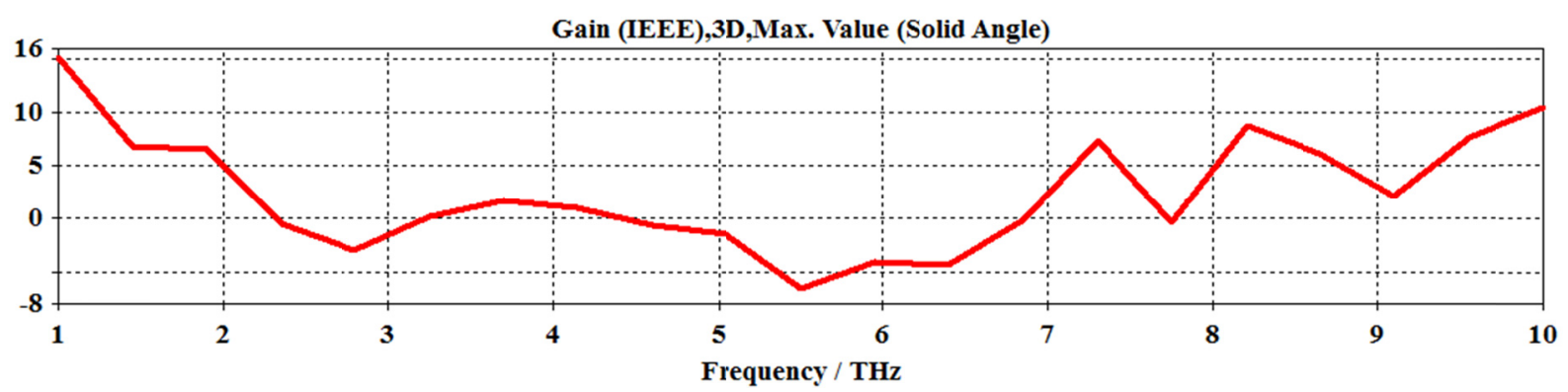

(b) Antenna gain

Figure A3. Antenna scattering parameter $S_{11}$ (a) and antenna gain (b) when $\mu_{\mathrm{c}}=0.4 \mathrm{eV}$

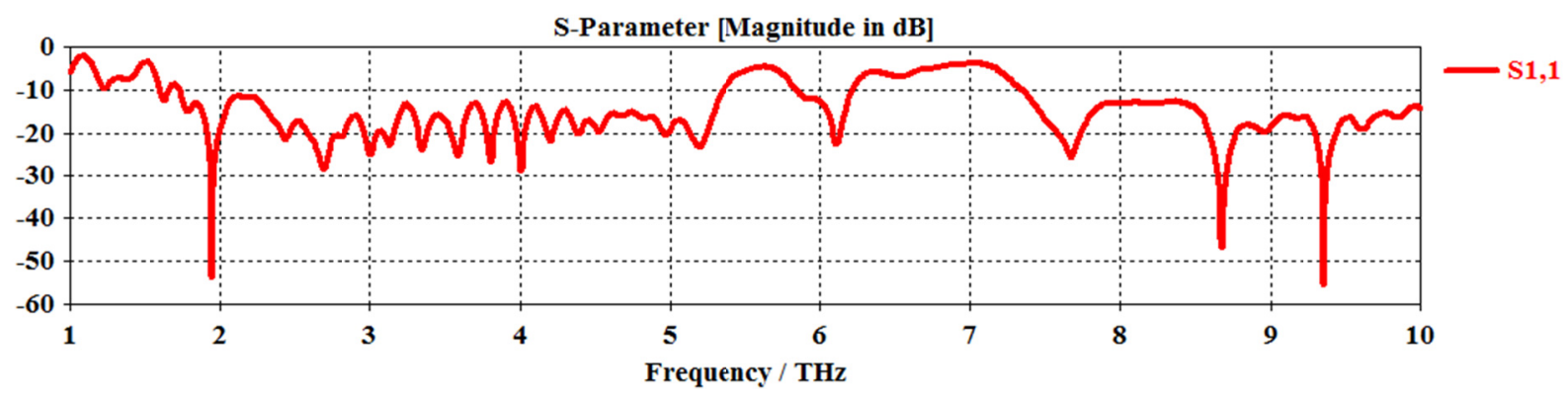

(a) Antenna scattering parameter $S_{11}$

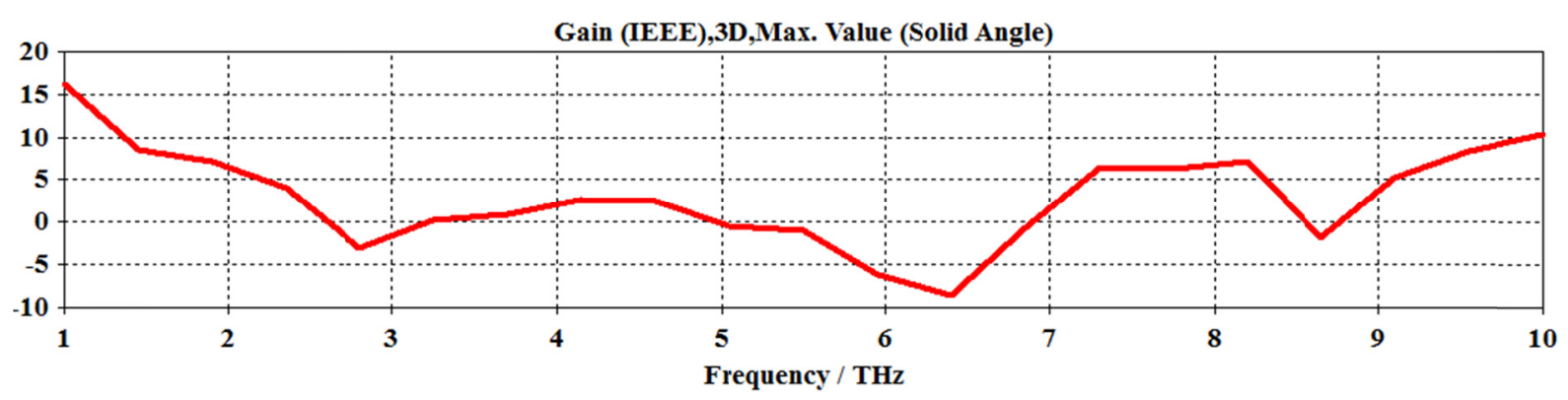

(b) Antenna gain

Figure A4. Antenna scattering parameter $S_{11}$ (a) and antenna gain (b) when $\mu_{\mathrm{c}}=0.5 \mathrm{eV}$

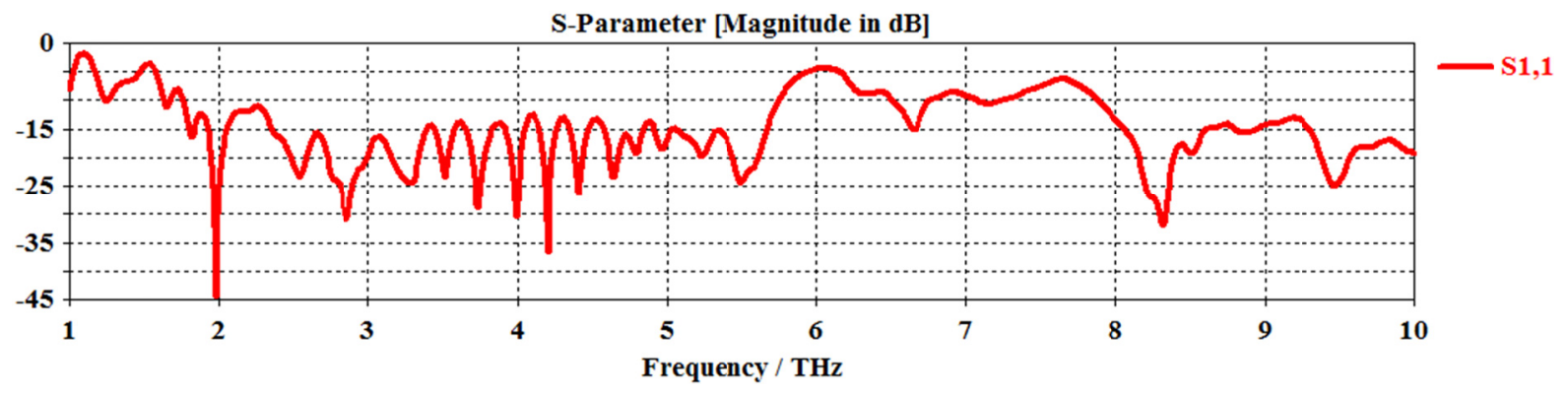

(a) Antenna scattering parameter $S_{11}$ 


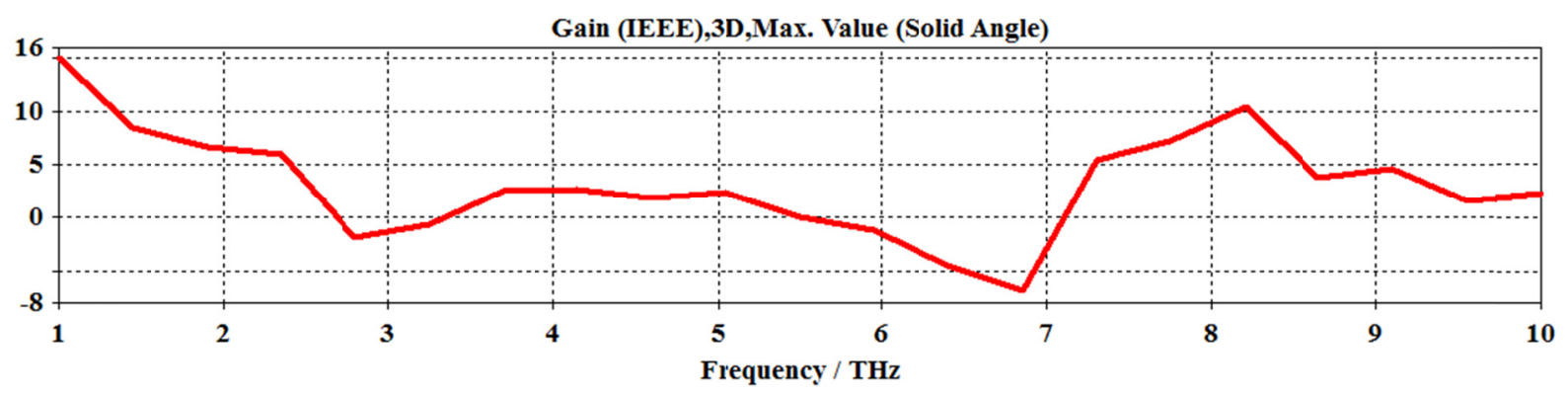

(b) Antenna gain

Figure A5. Antenna scattering parameter $S_{11}$ (a) and antenna gain (b) when $\mu_{\mathrm{c}}=0.6 \mathrm{eV}$

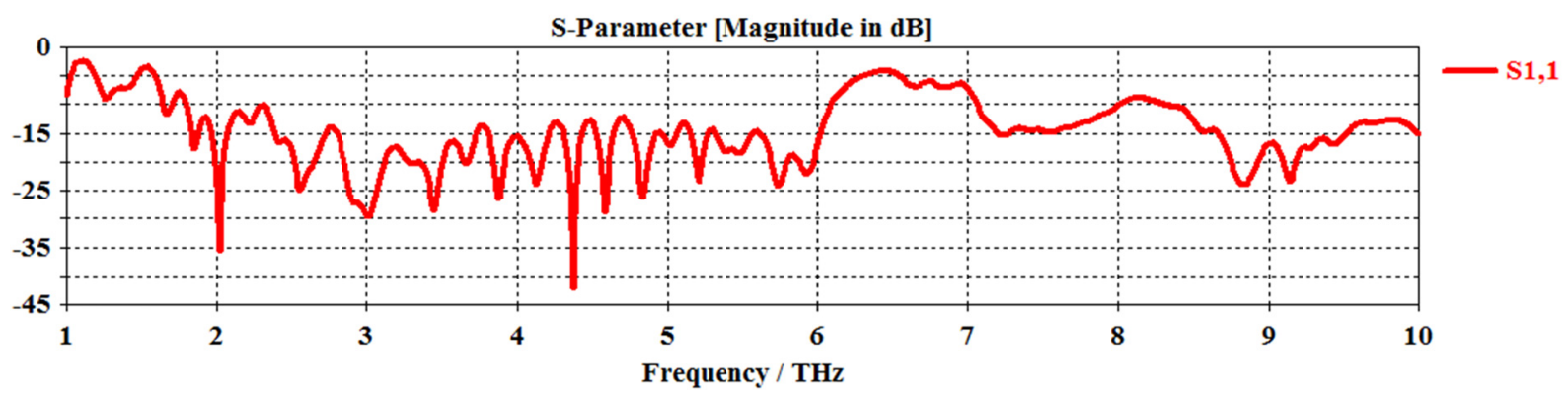

(a) Antenna scattering parameter $S_{11}$

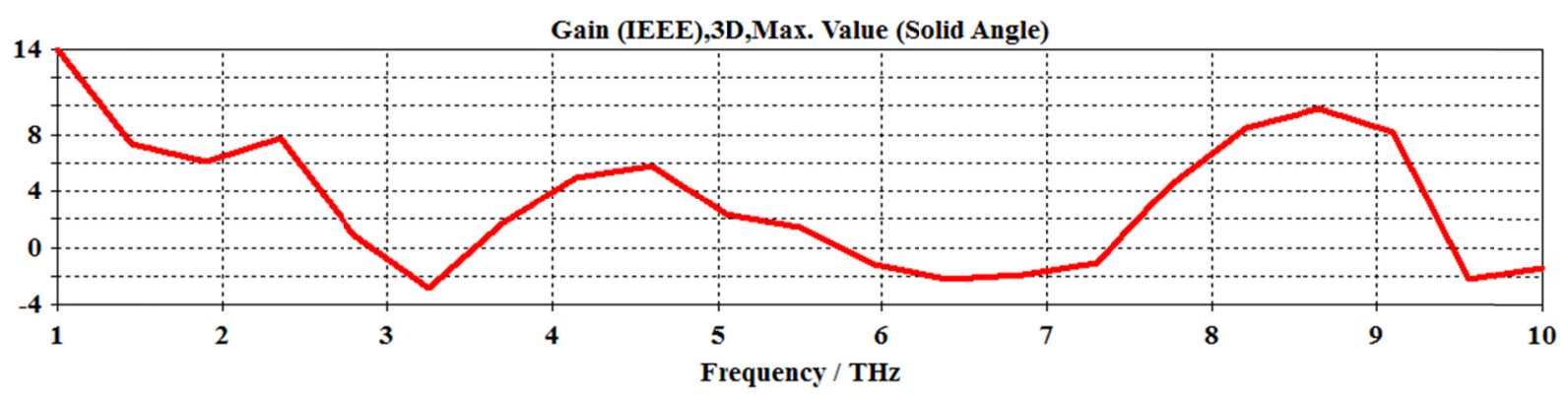

(b) Antenna gain

Figure A6. Antenna scattering parameter $S_{11}$ (a) and antenna gain (b) when $\mu_{\mathrm{c}}=0.7 \mathrm{eV}$

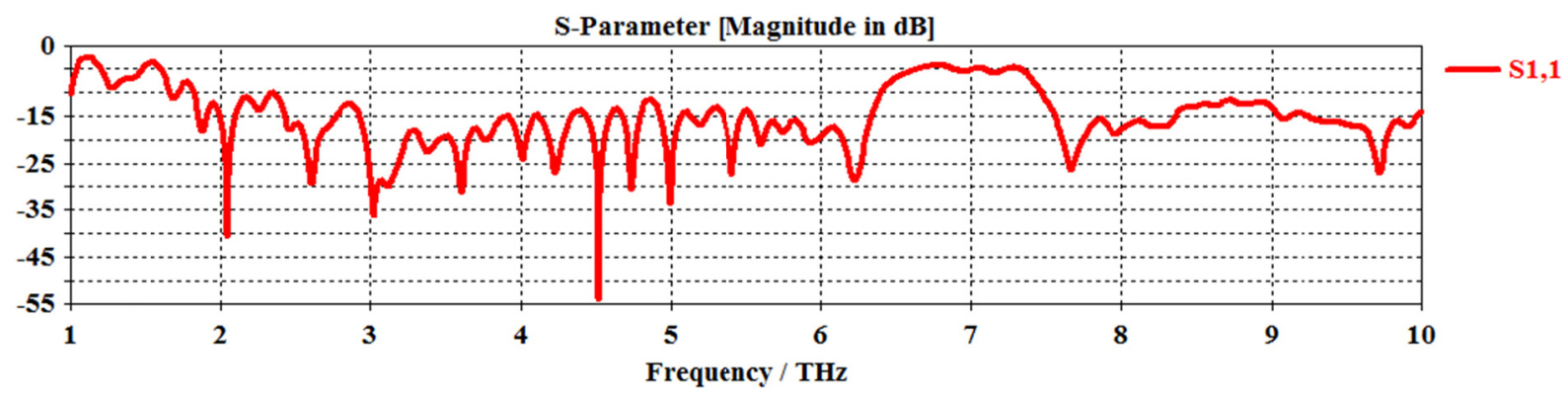

(a) Antenna scattering parameter $S_{11}$ 


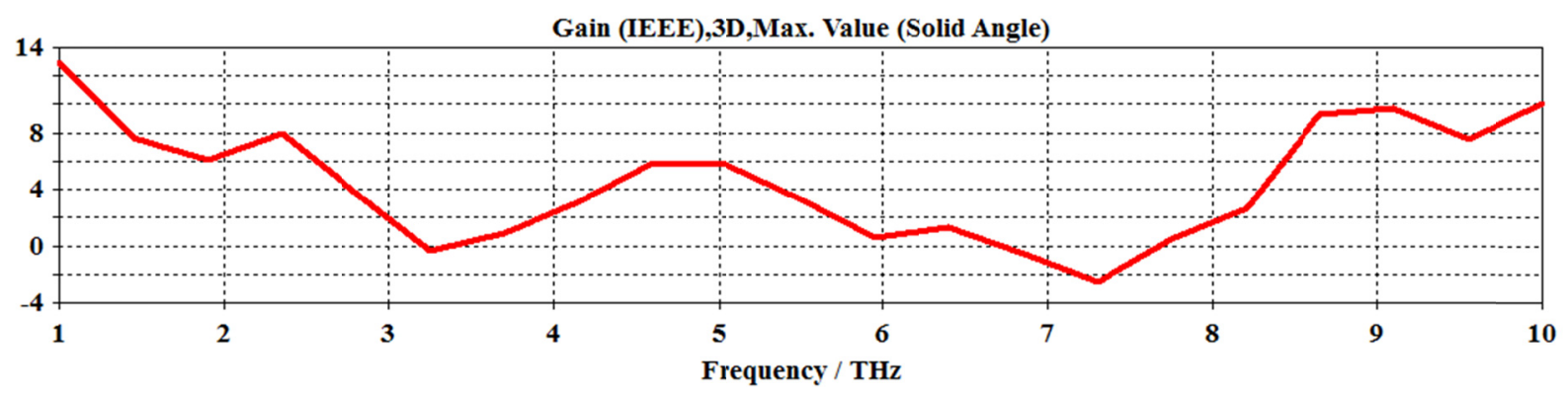

(b) Antenna gain

Figure A7. Antenna scattering parameter $S_{11}$ (a) and antenna gain (b) when $\mu_{\mathrm{c}}=0.8 \mathrm{eV}$

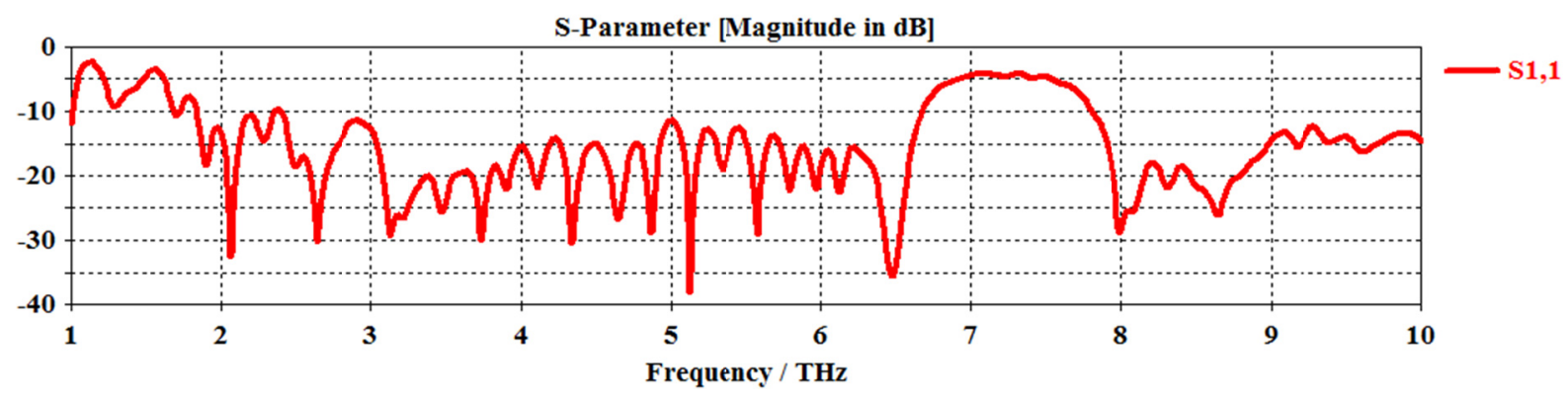

(a) Antenna scattering parameter $\mathrm{S}_{11}$

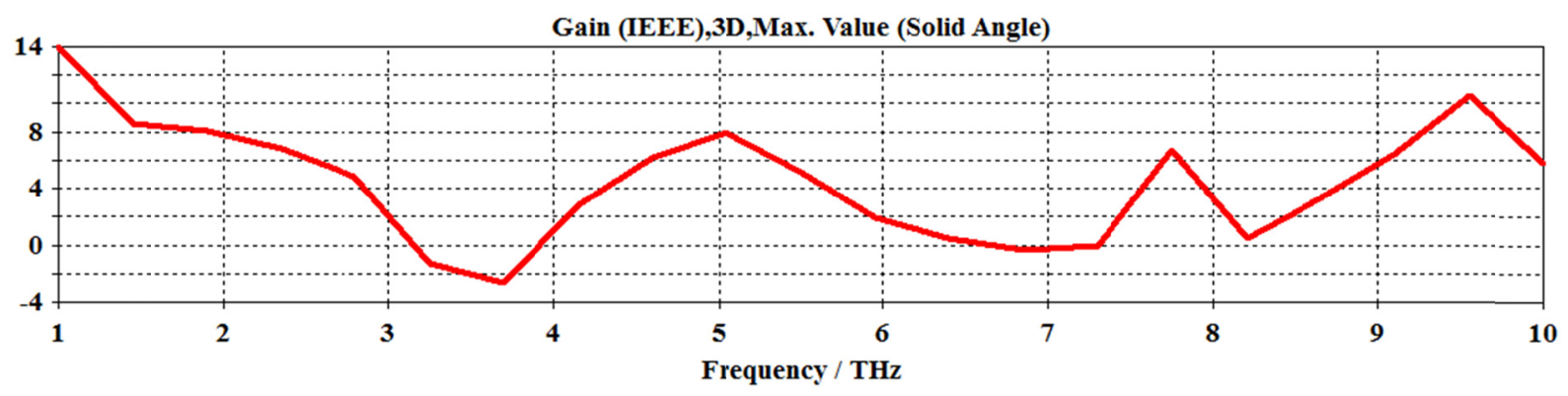

(b) Antenna gain

Figure A8. Antenna scattering parameter $S_{11}$ (a) and antenna gain (b) when $\mu_{c}=0.9 \mathrm{Ev}$

\section{Copyrights}

Copyright for this article is retained by the author(s), with first publication rights granted to the journal.

This is an open-access article distributed under the terms and conditions of the Creative Commons Attribution license (http://creativecommons.org/licenses/by/4.0/). 